\title{
Validation of structural effects mediated by MR-guided focused ultrasound on animal kidney ex vivo model
}

\author{
Timur Saliev ${ }^{1,2}$, I oannis Karakitsios ${ }^{1}$, Sarfraz Ahmad ${ }^{3}$, Stewart Fleming ${ }^{4}$, Andreas Melzer ${ }^{1}$ \\ 1. Institute for Medical Science and Technology, University of Dundee, United Kingdom. 2. Centre for Life Sciences, \\ Nazarbayev University, Astana, Kazakhstan. 3. Department of Urology, Ninewells Hospital, University of Dundee, United \\ Kingdom. 4. Medical Research Institute, School of Medicine, University of Dundee, United Kingdom.
}

Correspondence: Timur Saliev. Address: Institute for Medical Science and Technology, University of Dundee, Wilson House, 1 Wurzburg Loan, Dundee Medipark, Dundee DD2 1FD, Scotland, United Kingdom. Email: tim.saliev@gmail.com

Received: October 22, 2013

Accepted: March 31, 2014

Online Published: April 19, 2014

DOI : $10.5430 /$ jst.v4n2p18

URL: http://dx.doi.org/10.5430/jst.v4n2p18

\section{Abstract}

Introduction: MR-guided Focused Ultrasound (MRgFUS) has attracted the attention of researchers and clinicians as a potential modality for cancer treatment over the last decades. Despite recent progress, the real application of MRgFUS still remains a challenge due to problems with the optimization of ultrasound parameters and standardization of clinical protocol. In this study, we utilized an ex vivo animal model in order to elucidate the effect of focused acoustic energy on kidney tissue.

Material \& Methods: The explanted porcine kidney was sonicated under MR-guidance by using a clinical Focused Ultrasound (FUS) system (ExAblate 2000 Body system, InSightec, Haifa, Israel). The study employed MR-based temperature mapping (Proton Resonance Frequency method) for control of the ablation. The data of temperature measurement has been compared to histological analysis of treated tissues.

Results: The temperature mapping data demonstrated a rise of temperature at the focal point up to $44^{\circ} \mathrm{C}$ ( $\mathrm{SD} \pm 1$ ), which was thought to be sufficient enough to trigger hyperthermia effects. Histopathological analysis showed tissue destruction as a result of massive cavitation in treated tissues. The signs of mechanical damage were more pronounced in a place that was treated 240 seconds compared with the first location (sonicated 120 seconds).

Conclusions: The effect of FUS on the tissues of animal kidney was investigated. The achieved level of temperature rise in the focal point was high enough to induce hyperthermia suggesting possible clinical application. Histology of treated tissue indicated that its therapeutic effect was mediated by focused ultrasound. The correlation between duration of sonication and tissue damage was demonstrated.

\section{Key words}

Ultrasound, Bio-effects, Hyperthermia, Animal kidney, Histology

\section{Introduction}

The treatment of kidney cancer remains a challenge in modern urology. Although the treatment depends specifically on the type of the cancer, clinicians mainly rely on surgical interventions ${ }^{[1]}$. In addition to the classic open surgical approach, 
minimally invasive methods such as a laparoscopic or robotic surgery have been applied successfully to renal cancer management.

Parallel to evolution of surgical treatment, other therapeutic modalities (including cytokine and immune therapies) were proposed and developed over the past years. Despite some promising results of preliminary studies, there are no verified data confirming the effectiveness of these novel agents in clinical practice ${ }^{[2]}$. Another approach for management of renal cancer is targeted therapy, particularly the inhibition of VEGF (Vascular Endothelial Growth Factor) and mTOR (mammalian Target Of Rapamycin) pathways. These drugs are useful in adjuvant settings for metastatic disease ${ }^{[3]}$.

As an alternative to invasive surgical approach, range of non-surgical physical modalities are investigated for renal cancers including cryotherapy, radio-frequency ablation and high intensity focused ultrasound surgery ${ }^{[4-6]}$. In terms of accuracy and targeting, a combination of MRI and focused ultrasound has been considered as the best option for kidney ablation ${ }^{[7,8]}$. MR-guided therapy provides a precise navigation of ultrasound beam along with real-time temperature feedback, which is crucial for effective and safe tissue ablation.

The aim of this study was to scrutinize the impact of high intensity ultrasound field on kidney tissue on an ex-vivo animal model for the optimization of the treatment protocol. Histological analysis was applied to provide evidence of effectiveness of ablation elicited by the MR-guided high intensity focused ultrasound.

Figure 1. Experimental arrangement, showing:

A) Coronal MR image of the kidney in the chamber (green dot is sonication spot);

B) Sagittal MR image with representation of ultrasound beam path (blue) (ExAblate 2000 Body system, InSightec, Haifa, Israel);

C) Schematic draw of sonication setup

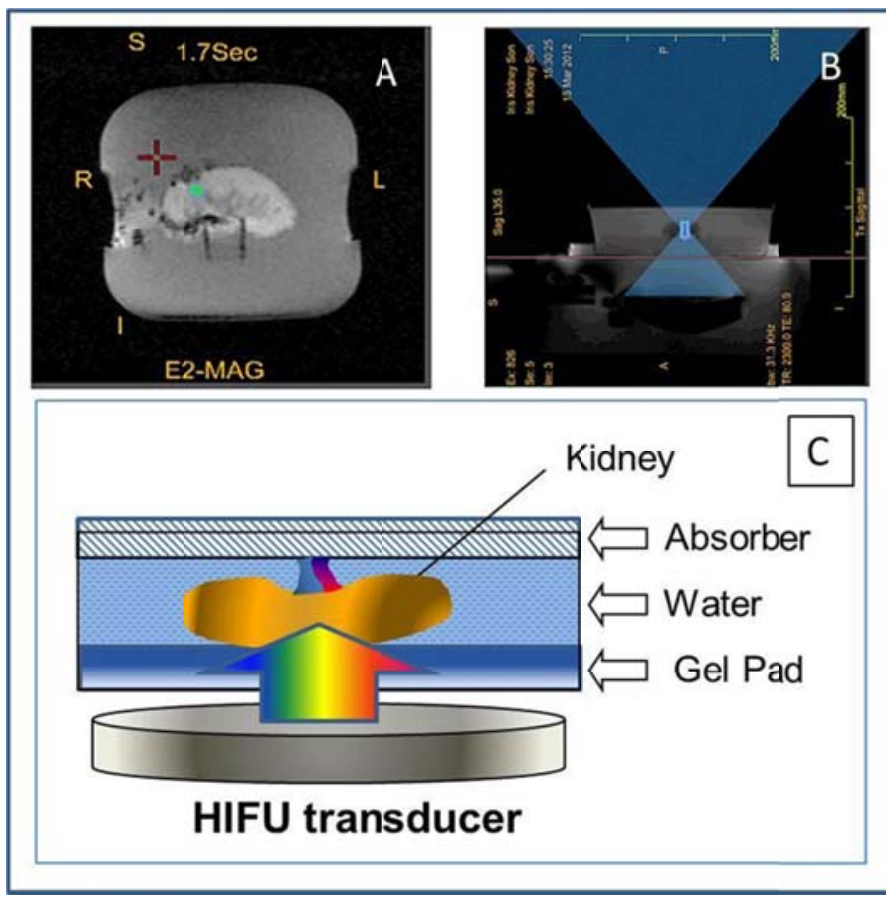

\section{Materials and methods}

\subsection{Target organ and sonication set-up}

The explanted animal kidney was placed into a custom-made plastic chamber (Insightec Ltd, Israel). The dimensions of the chamber were as the followings: length $20 \mathrm{~cm}$, width $20 \mathrm{~cm}$ and height $6 \mathrm{~cm}$. The chamber had an acoustic window on the bottom (size $11.4 \mathrm{~cm} \times 10.4 \mathrm{~cm}$ ) sealed by polyethylene film (60 microns). A degassed Gel Pad (Gel Pad UF $25 \mathrm{~mm}$, Insightec Ltd, Israel) was placed on the bottom of the chamber for optimal interface between the organ and ultrasound. The 
sonication chamber was filled with degassed water and was covered by an acoustic absorber (Precision Acoustics Ltd., UK) for neutralization of ultrasound standing waves. The scheme of sonication set-up is shown in Figure 1.

\subsection{Selecting the target areas and treatment}

The kidney was subjected to pre-treatment planning MR imaging (Signa HDxt 1.5 Tesla, GE Healthcare, USA). The following MRI parameters were used: TE 80.9, TR 2300, Bandwidth $31.3 \mathrm{KHz}$. After identifying target zones, the sonication was conducted under MR-guidance by using a clinical Focused Ultrasound system (ExAblate 2000 Body system, InSightec, Haifa, Israel). The kidney was treated by FUS at two different spots within the renal medulla area. The applied acoustic energy was 1064 Joules and the frequency was $1 \mathrm{MHz}$ in both locations. The first focal point was treated for $120 \mathrm{sec}$, whilst the second one was heated for $240 \mathrm{sec}$. The monitoring of temperature level at the focal points was conducted by using MR-based Proton Resonance Frequency (PRF) method.

The Proton Resonance Frequency imaging is one of the most reliable methods for temperature mapping. It based on the dependence of temperature on the chemical field shift of water protons in the tissues. The chemical shift can be extracted from the phase mapping (on RF-spoiled gradient-echo images).

The temperature difference could be derived by using the following equation ${ }^{[9]}$ :

$$
\Delta T=\frac{\varphi(T)-\varphi\left(T_{0}\right)}{\gamma \alpha B_{0} T E}
$$

where $\varphi(T)$ is the phase in the current image,

$\left(\mathrm{T}_{0}\right)$ is the phase of a reference (baseline) image at a known temperature,

$\gamma$ is the gyromagnetic ratio, $\alpha$ is the PRF change coefficient,

$\mathrm{B}_{0}$ is the magnetic field strength,

TE is the echo time.

It must be noted that for this method the reference (baseline temperature) was pre-requisite.

As sonication can induce cavitation effects overshadowing and mimicking temperature rise, the level of inertial cavitation was monitored by the hydrophone incorporated into the transducer of the FUS system.

\subsection{Histological analysis of treated tissue}

After the treatment three tissues were taken from each ablated spot using a semi-automatic biopsy system under MRI navigation (14 Gauge; Somatex Medical Technologies GmbH, Rostock, Germany). The samples of the intact tissue were taken at $5 \mathrm{~cm}$ distance from the ablated point. The dimensions of the analysed tissues were $10 \mathrm{~mm}$ (length) and $2 \mathrm{~mm}$ in diameter.

The obtained treated and untreated kidney tissues were subjected to histological analysis. The samples were fixed in $10 \%$ neutral buffered formalin, paraffin-embedded, and then sectioned at 4- $\mu \mathrm{m}$ thickness. After deparaffinization and gradual hydration, the samples were stained using haematoxylin-eosin. The sections were examined on a Nikon Eclipse 600 microscope (Nikon, Japan) and images were captured exploiting a Nikon DX1200 digital camera (Nikon, Japan). The analysis of the ablated and normal kidney tissues was conducted by specialist-pathologist who was unaware about details of the experiments to provide for an objective assessment. 


\section{Results}

The temperature elevation up to $44^{\circ} \mathrm{C}(\mathrm{SD} \pm 1)$ was detected by the PRF-method in the first focal location, which was sonicated for 120 seconds. Doubling of the treatment time (on the second location) resulted in thermal rise up to $44.7^{0} \mathrm{C}$ $(\mathrm{SD} \pm 1.15)$.

The data of histological analysis demonstrate signatures of the tissue deterioration caused by a high intensity acoustic field for both spots. All samples taken from the first focal location (sonicated for 120 seconds) indicated mechanical damage (Figure 2) such as a disruption of plasma membranes, loss of cellular integrity, dissolution of nuclei and formation of holes as a result of inertial cavitation and formation of large steam vacuoles.

Figure 2. Image of histologic cross section of kidney zone treated by ultrasound during 120 seconds (400X).

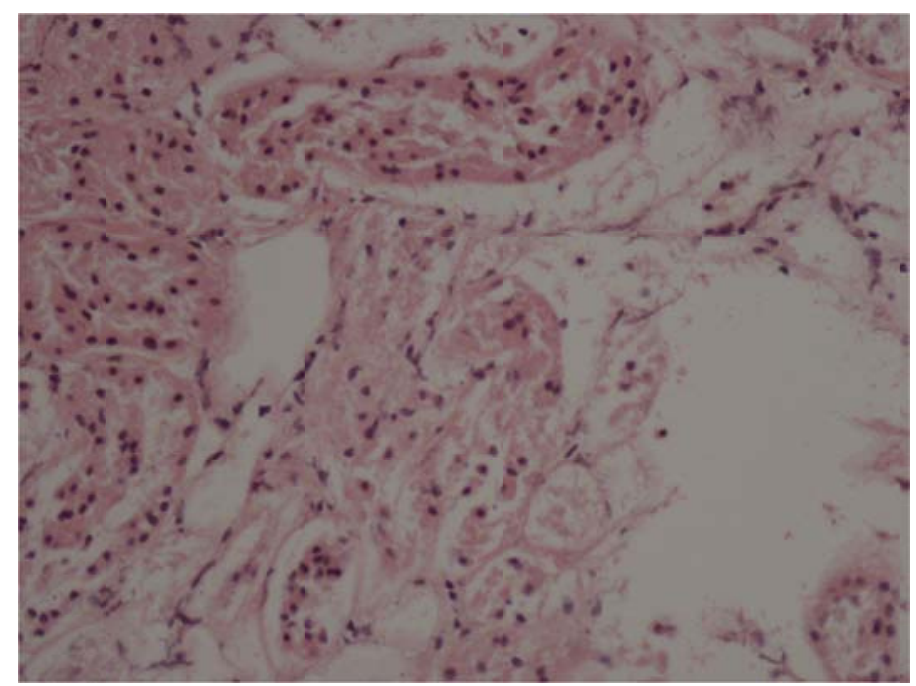

As it can be seen from the histological analysis, the signs of tissue destruction are more visible in the samples from the second ablated spot (treated for $240 \mathrm{sec}$ ) (Figure 3) compared to the histological picture of intact kidney tissue (Figure 4) and tissue from the spot treated for $120 \mathrm{sec}$ (Figure 2). It includes an obliteration of the morphological structure, defragmentation of the nuclei and the morphological attributes of cell lysis. The samples demonstrated a well-defined discoloration as a consequence of massive escape of hemoglobin. This finding directly indicates the intensive destruction of cellular membranes triggered by the ultrasound.

Figure 3. Image of histologic cross section of kidney zone treated by ultrasound during 240 seconds (400X).

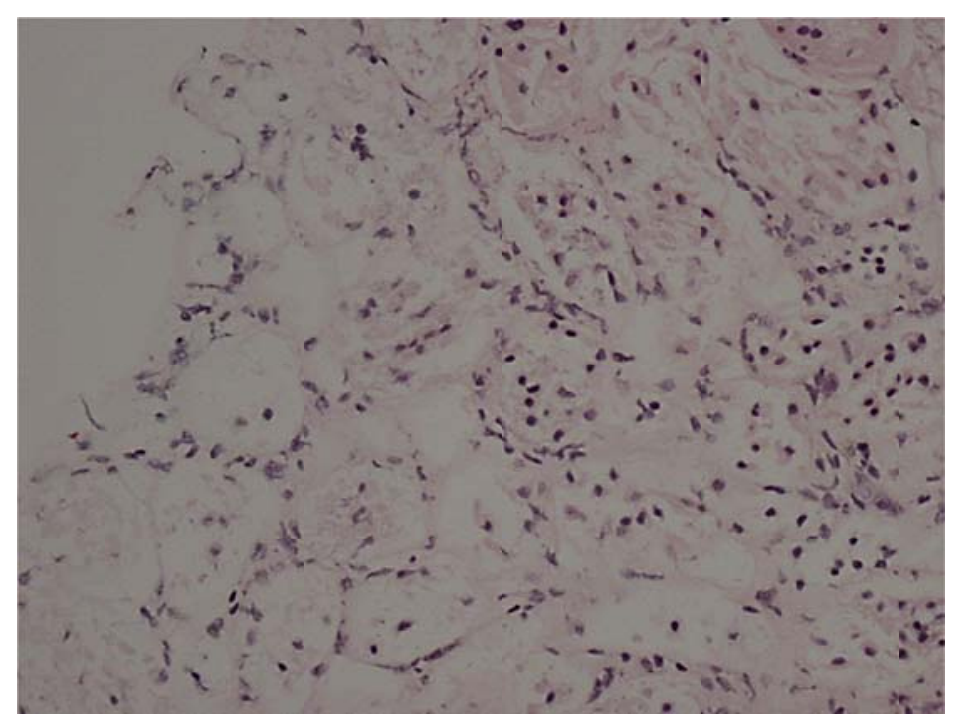


Figure 4. Image of histologic cross section of intact animal kidney tissue (400X).

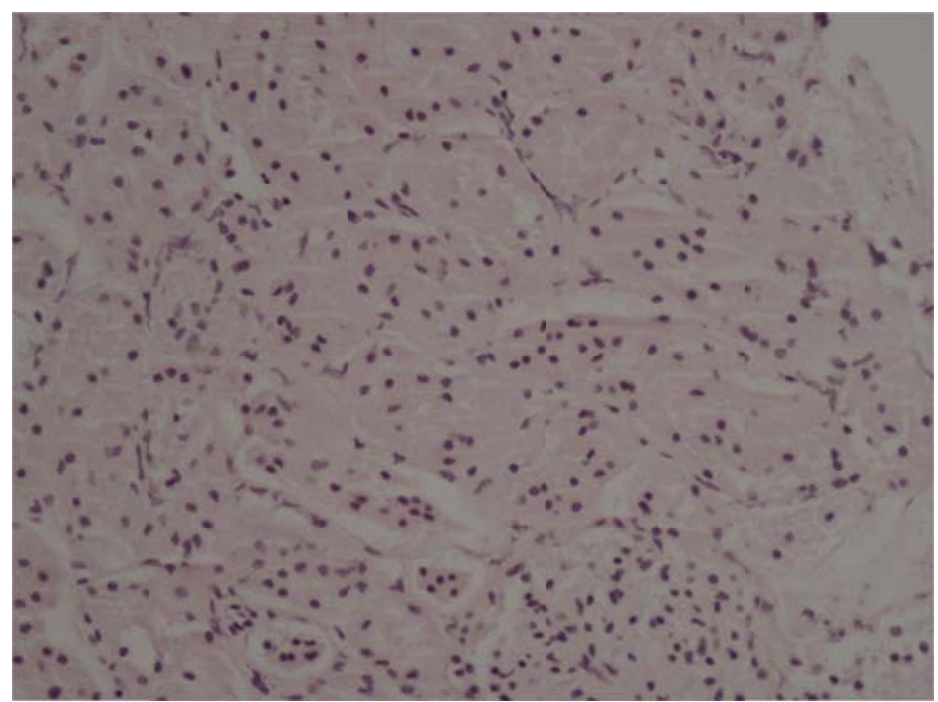

\section{Statistical analysis}

Minimum three temperature measurements have been conducted for each ablated spots, which enabled calculation of standard deviations and means. Non-parametric test Mann-Whitney-Wilcoxon has been applied in order to analyse significance of acquired data. The analysis revealed that the distributions of temperature in two sub-groups (treated 120 $\mathrm{sec}$ and $240 \mathrm{sec}$ correspondingly) did not significantly differ (Mann-Whitney $\mathrm{U}=3, \mathrm{n} 1=\mathrm{n} 2=3, P<0.05$ two-tailed).

\section{Discussion}

Focused ultrasound is a promising modality for non-invasive treatment of different types of organ cancers, including renal cell carcinoma (RCC) ${ }^{[6-8,10]}$. It has been demonstrated that the application of high intensity acoustic field can provide a possibility of avoiding undesirable damage of healthy tissues without surgical trauma and a relatively short time of treatment ${ }^{[10-12]}$. Although some progress in experimental studies of exploiting the ultrasound for targeted destruction of kidney tissues and preliminary clinical results has been made over last decade, implementation of this modality in routine clinical practice is still under development ${ }^{[13]}$. With regard to this, the combination of MR imaging and focused ultrasound offers an ideal option for tumor ablation due to precise targeting and real-time temperature feedback. Apart from thermal mapping, the MR-imaging provides a feasibility of evaluation of treated site of the tissue. Damianou and co-workers conducted a study of using MR-guided high intensity focused ultrasound for validation of ablation of the animal kidney ${ }^{[8]}$. They discovered different options for MR-visualization of lesions of the tissue. They reported about excellent contrast between lesion and intact tissues by utilizing T1-weighted (with TR 200-400 ms) and T2 (with TE 16-32 ms) Fast Spin Echo imaging sequences.

However in this study we used histological analysis in order to assess the effectiveness of MR-guided ultrasound ablation of kidney tissues. The second goal of our work was to investigate the correlation between of duration of the treatment and tissue damage.

The obtained histological data indicate two possible mechanisms of ultrasound-induced effect: hyperthermia and inertial cavitation. The detected hyperthermia (about $44^{0} \mathrm{C}$ ) suggests that this temperature level is high enough to trigger cell lysis and programmed cell death ${ }^{[14]}$. Apart from that, the samples from both ablated spots have signatures of mechanical damage including disruption tissue texture and multiple holes. Those holes are a consequence of massive cavitation events detected during experiments by the hydrophone incorporated into the transducer of the FUS system (ExAblate 2000 Body system, InSightec, Haifa, Israel). It has been thought that the inertial cavitation is responsible for disruption of cellular 
membrane and cell death ${ }^{[15-17]}$. In particular, the cavitation is more pronounced on second focal location, which has all signs of cells disintegration and dramatic escape of hemoglobin (Figure 3). The high level of inertial cavitation could be a cause of similarity of maximal temperatures detected on both spots.

We did not observe a significant temperature increase linked to augmentation of the duration of sonication. Usually such prolonged treatment leads to the formation of micro-bubbles inside the tissue, particularly within intercellular space. Accordingly to the literature, the micro-bubbles cloud does act as a shield, which causes a significant attenuation of acoustic propagation and consequently the reduction of the heating effect ${ }^{[18]}$.

\section{Conclusions}

The acquired data suggest the feasibility of induction of hyperthermia by using moderate acoustic energy. This approach might be harnessed for triggering apoptosis in tumor tissues without risk of ablating neighbor soft tissues. The data of histology indicate that ultrasound-elicited tissue destruction is time-dependent, where prolongation of treatment period seems to be more effective for cancer therapy.

These findings demonstrated the potential of MR-guided ultrasound surgery as a modality for non-invasive treatment of renal cell carcinoma with minimal structural damage of the surrounding tissue. In the next step an orthotropic tumor model on re-perfused porcine kidneys will be established for further validation.

\section{Acknowledgements}

The authors are thankful to financial assistance provided by the project FUSIMO ("Patient specific modelling and simulation of focused ultrasound in moving organs") funded under the EU's Seventh Framework Programme for Research and Technological Development.

\section{Declaration of interest}

The authors do report no conflicts of interest. The authors alone are responsible for the content and writing of the paper.

\section{References}

[1] Nelson EC, Evans CP, Lara PN, Jr. Renal cell carcinoma: current status and emerging therapies. Cancer Treat Rev. 2007 May; 33(3): 299-313. PMid:17329029 http://dx.doi.org/10.1016/j.ctrv.2006.12.005

[2] Thomas JO, Tawfik, Ossama, W. Recent advances in the diagnosis of renal cell carcinoma. Diagnostic Histopathology. 2008; 14(4): 157-63. http://dx.doi.org/10.1016/j.mpdhp.2008.02.007

[3] Thillai K, Allan S, Powles T, Rudman S, Chowdhury S. Neoadjuvant and adjuvant treatment of renal cell carcinoma. Expert Rev Anticanc. 2012; 12(6): 765-76. PMid:22716493 http://dx.doi.org/10.1586/era.12.56

[4] Powell T, Whelan C, Schwartz BF. Laparoscopic renal cryotherapy: biology, techniques and outcomes. Minerva Urol Nefrol. 2005 Jun; 57(2): 109-18. PMid:15951735

[5] Rendon RA, Gertner MR, Sherar MD, Asch MR, Kachura JR, Sweet J, Jewett MA. Development of a radiofrequency based thermal therapy technique in an in vivo porcine model for the treatment of small renal masses. J Urol. 2001 Jul; 166(1): $292-8$. http://dx.doi.org/10.1016/S0022-5347(05)66148-4

[6] Ritchie RW, Leslie T, Phillips R, Wu F, Illing R, ter Haar G, Protheroe A, Cranston D. Extracorporeal high intensity focused ultrasound for renal tumours: a 3-year follow-up. BJU Int. 2010 Oct; 106(7): 1004-9. PMid:20230379

http://dx.doi.org/10.1111/j.1464-410X.2010.09289.x

[7] Damianou C. MRI monitoring of the effect of tissue interfaces in the penetration of high intensity focused ultrasound in kidney in vivo. Ultrasound in medicine \& biology. 2004; 30(9): 1209-15. PMid:15550324

http://dx.doi.org/10.1016/j.ultrasmedbio.2004.08.010

[8] Damianou C, Pavlou M, Velev O, Kyriakou K, Trimikliniotis M. High intensity focused ultrasound ablation of kidney guided by MRI. Ultrasound Med Biol. 2004 Mar; 30(3): 397-404. PMid:15063522 http://dx.doi.org/10.1016/j.ultrasmedbio.2003.10.018 
[9] Cernicanu A, Lepetit-Coiffe M, Roland J, Becker CD, Terraz S. Validation of fast MR thermometry at $1.5 \mathrm{~T}$ with gradient-echo echo planar imaging sequences: phantom and clinical feasibility studies. Nmr in Biomedicine. 2008Oct; 21(8): 849-58.

PMid:18574794 http://dx.doi.org/10.1002/nbm.1267

[10] Leslie TA, Kennedy JE, Illing RO, Ter Haar GR, Wu F, Phillips RR, Friend PJ, Roberts ISD, Cranston DW, Middleton MR. High-intensity focused ultrasound ablation of liver tumours: can radiological assessment predict the histological response? Br J Radiol. 2008; 81(967): 564-71. PMid:18559903 http://dx.doi.org/10.1259/bjr/27118953

[11] Quesson B, Merle M, Kohler MO, Mougenot C, Roujol S, de Senneville BD, Moonen CT. A Method for MRI Guidance of Intercostal High Intensity Focused Ultrasound Ablation in the Liver. Medical Physics.2010; 37:2533-2540. PMid:20632565 http://dx.doi.org/10.1118/1.3413996

[12] Malietzis G, Monzon L, Hand J, Wasan H, Leen E, Abel M, Muhammad A, Price P, Abel P. High-intensity focused ultrasound: advances in technology and experimental trials support enhanced utility of focused ultrasound surgery in oncology. Brit J Radiol. 2013 Apr; 86(1024). PMid:23403455 http://dx.doi.org/10.1259/bjr.20130044

[13] Marberger M. Ablation of renal tumours with extracorporeal high-intensity focused ultrasound. BJU international. 2007; $99(5 \mathrm{Pt}$ B): 1273-6. PMid:17441923 http://dx.doi.org/10.1111/j.1464-410X.2007.06817.x

[14] Feril LB, Jr., Kondo T, Zhao QL, Ogawa R. Enhancement of hyperthermia-induced apoptosis by non-thermal effects of ultrasound. Cancer Lett.2002 Apr 8; 178(1): 63-70. http://dx.doi.org/10.1016/S0304-3835(01)00826-6

[15] Wu J, Nyborg WL. Ultrasound, cavitation bubbles and their interaction with cells. Adv Drug Deliv Rev. 2008 Jun 30; 60(10): 1103-16. PMid:18468716 http://dx.doi.org/10.1016/j.addr.2008.03.009

[16] Guzman HR, Nguyen DX, Khan S, Prausnitz MR. Ultrasound-mediated disruption of cell membranes. II. Heterogeneous effects on cells. J Acoust Soc Am. 2001 Jul; 110(1): 597-606. PMid:11508985 http://dx.doi.org/10.1121/1.1376130

[17] Hallow DM, Mahajan AD, McCutchen TE, Prausnitz MR. Measurement and correlation of acoustic cavitation with cellular bioeffects. Ultrasound Med Biol. 2006 Jul; 32(7): 1111-22. PMid:16829325

http://dx.doi.org/10.1016/j.ultrasmedbio.2006.03.008

[18] Nyborg WL. Ultrasound, contrast agents and biological cells; A simplified model for their interaction during in vitro experiments. Ultrasound Med Biol. 2006 OCT; 32(10) :1557-68. PMid:17045877

http://dx.doi.org/10.1016/j.ultrasmedbio.2006.05.032 